\title{
Smart Equipment Charger
}

\author{
G.Shobana, M.Suguna
}

\begin{abstract}
In today's world, the usages of electronic devices are increased. The most of the devices are depending on power charger, the battery chargers will also varying from different applications like mobile phone charger, vehicles battery charging, electric vehicle batteries chargers and also charging stations. Many users are charging their mobile phone over the night. Due to overnight charging of battery which accelerates to a high average state of charge, as the result battery aging come to exists. Vampire power is one of the daunting issues faced by the world. In the proposed system when battery is full it will automatically stop the power flowing to the battery. The battery level of the mobile phone are tracked by sensors and Arduino for automatically switch off the power. This product is very economical and can be used in any kind of battery charging. As it involves simple components trouble shooting is very easy in case of occurrence of any fault. As the result it helps to conserve amount of power and increase the battery life.
\end{abstract}

Keywords: Vampire power, Arduino, aging, automatic power off, single phase current, Voltage

\section{INTRODUCTION}

Now a day's, many applications are simply performed by various electronic appliances. Thus, in numerous electronic appliances are emerging day by day. The overnight charging of mobile phone, it may degrade the battery life and performance of the device. The device should regularly monitor the battery level, so that the power off has to be done after the completed charging. The devices are integrated with IoT devices to get the real time status of charging percentage of the mobile. Based on charging percentage automatic power cut off to the devices. The charging components of devices is paired with the IoT devices, based on that charging of the circuits is performed.

\section{RELATED WORKS}

In the Famous magazine "METRO" reveals that "how much it really costs to charge up your smartphone every day". According to measurement from Lawrence Berkley National Laboratory, the average cell phone draws 3.68Wof power from the outlet while it's charging and $2.24 \mathrm{~W}$ when charged. Normally people used to charge their phones during night times and it is being charger for around 7-8 hours. A smart phone takes about 4 hours to get charged fully. After fully charging, charger consumes $3 \mathrm{~W}$ of waste power for 3 hours which will be acquired by the charger. Thus, $3 \mathrm{~W} * 3$ Hours $=9 \mathrm{~W}$ of waste power is consumed by one charger per day.

According to the report from "ANDROID AUTHORITY "stating that "Why phones explode sometimes, and what you can do to protect yourself and your phone" reveals the cons of overcharging of our mobile phone. If people charge

Revised Manuscript Received on August 14, 2019.

G.Shobana, Assistant Professor, Department of CSE, Kumaraguru College of Technology, Coimbatore, Tamilnadu, India.

Dr.M.Suguna, Assistant Professor, Department of CSE, Kumaraguru College of Technology, Coimbatore, Tamilnadu, India. their phones every night for a year, we are up to a grand total of $3.2 \mathrm{KW}$ of electricity. Even though it may be seen as a small wastage in an individual perspective, it will have a very large impact when taken as a big country like India. In a whooping population of 126 corers, it would really matter even if 40 crore people charge their phone overnight. 40 crores * $3.2 \mathrm{KW}=1300 \mathrm{GW}$ amount of power wasted in India due to night charging.

Ying-Wen Bai(2017) "Automatic charging voltage" In this design wireless communication is used for message transmission of smart charger for automatic charging of current and voltage. The current and voltage can be adjusted to different temperatures for safety pupose. The battery charging status will be given to the user in the platform of the smart phones. If there is some abnormal status in the battery charging, it will be intimate to the user by some message transmission. The charging procedure will vary from different characteristics of the phone. So the user can set the threshold value for charging their phone.

Fuka Ikeda(2017) "source voltage and load currents conditions", this paper the smart charger was used for electrical vehicle with the single phase three -wire distribution for constant dc- capacity voltage control. The power flow to pulse which contains three legs, width modulated rectifier which act as smart charger as result the constant dc- capacity voltage control are used maintain the balanced current with unity power factor by both charging and discharging operations in Electrical vechicles.

Mauricio Restrepo "Bidirectional Smart Charger", It has 4 quadrants P-Q plane with single-phase bidirectional electric vehicle $(\mathrm{EV})$ charger. This system uses steady-state and step responses to validate the vehicle. The validation process is based on the actual responses of a bidirectional charger prototype with different $\mathrm{P}-\mathrm{Q}$ requests. This model is used in the time-domain simulations as EV integration studies in low-voltage distribution networks. Now a day's, mobility of electric vehicle are increased that leads to the growth of vehicle to grid technology. In LV distributed networks, power flow between the battery of electric vehicle and the power for active and reactive power in LV networks

Manoj Kumar, Deepak Lama (2015) had used the PhotoVoltaic (pv) solar charge which controls the works with DC-DC converter topology for battery charging. The automatic on or off switch modules with works when photovoltaic charger combines with regulated voltage to process the charging. While designing the battery number cycles we can recharges can be predicted, in order to increase the life time of battery, the charge the battery only after the power reaches some threshold values. Here regulated IC used to regulate voltage DC-DC converter [7]. 


\section{PROPOSED WORK}

The proposed method uses the smart charger that can be used to conserve power in any charging devices especially mobile phone. In this system the some parameter such as voltage, current, power are consider for evaluation continuously. Android Application and Arduino are used to sense the phone battery level on each internal of time. The data which is sensed by the android application and it sends a signal to the Arduino. The Arduino now gives an output voltage to the tripper circuit. The tripper circuit now trips the circuit open with help of a Relay. Once the charger circuit is tripped off there is no power supply to the charger thereby saving the power. Even though, the switch is in mechanically ON state, it is electrically in OFF condition. The architecture diagram of smart charger is shown in the figure 3.1

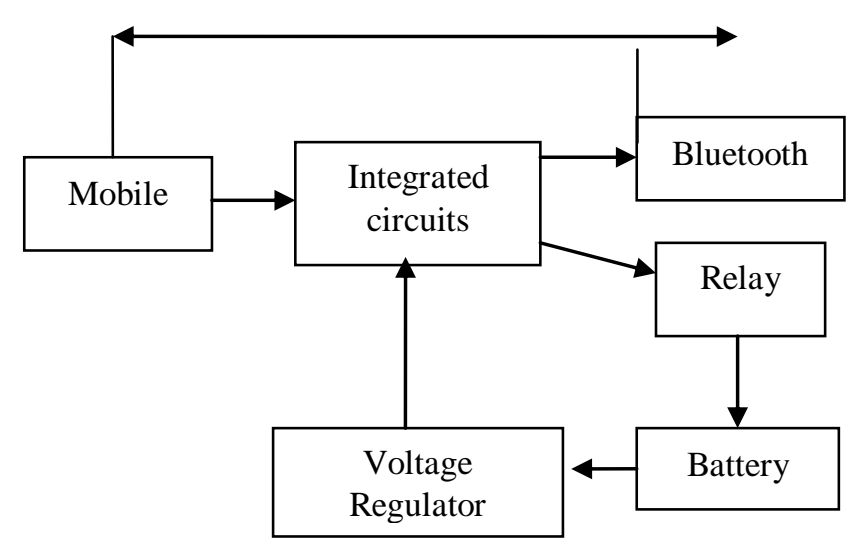

Figure 3.1: Architecture diagram for smart charger

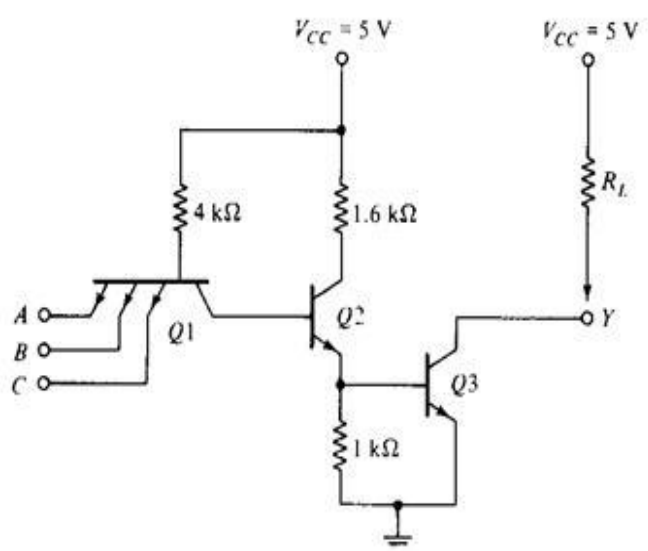

Figure 3.2: Circuit Diagram

Figure 3.2 explains the circuit diagram of the application. In which Q1, Q2, Q3 represents NPN transistors, A, B, C represents relay coils

$-\mathrm{W}$

Q1, Q2, Q3 -

$\mathrm{A}, \mathrm{B}, \mathrm{C}$ is called as Resistors. $5 \mathrm{~V}$ voltage current is passed to the circuits

npn transistors

relay coils

\subsection{Sensing circuit}

To senses the battery percentage of the smart phone, the android application is developed to sense the battery. The application in smart phone send a signal to the IC (integrated circuit) which will contain transformer for sending the data in correct voltage. Once when the mobile phone's battery attains $100 \%$ of charge, the IC drives the relay circuit to make it as NO (Normally Open). The Bluetooth module $\mathrm{HC}-05$ is used for wireless serial connection. It acts in Master/slave module. Role of module will be configured only by AT commands. Vcc and Gnd of the module of the HC-05 to Vcc and Gnd of Arduino. The Bluetooth serial signal sending PIN (TXD) is connected to Bluetooth serial signal receiving PIN (RXD) of Arduino and RXD pin goes to TXD pin of Arduino i.e (digital pin 0 and $1)$.

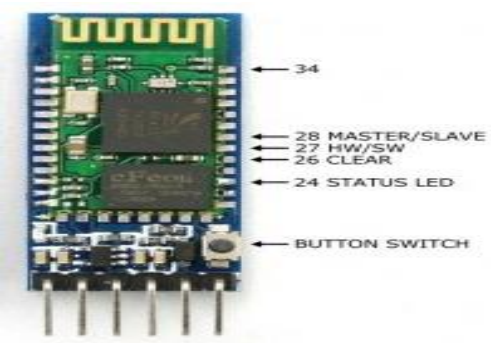

Figure 3.3 Bluetooth HC-05

\subsection{Tripper Circuit}

Relay is operated by the driver circuit (Transistortransistor logic) after the signal sent from the IC on sensing battery percentage. Once the charger circuit is tripped off there won't be any more power supply to the charger. The relay operates (drops-off) after a delay and the indicator LED turns red. The relay requires $\mathrm{AC}$ or DC voltage values. This voltage can be the same as that of the supervised circuit or it could be a separate source with same magnitude (AC or DC).

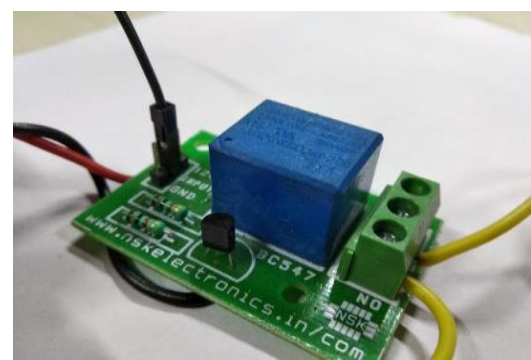

Figure 3.4 Relay Circuit

\subsection{Display Segment}

Android Application developed in the mobile show status of the connectivity. It will sense the battery level of a mobile phone and send the signal to the Arduino. When the battery level is full then the arduino will activate the tripper circuit to trip and the connection is closed to the mobile battery now no current will pass to the mobile. This Android Application is used to sense battery level. 


\section{RESULT}

In the figure 3.4 mobile phone will charge until some threshold value as $95 \%$, after that the relay will be discontinued the current flow in the circuits.

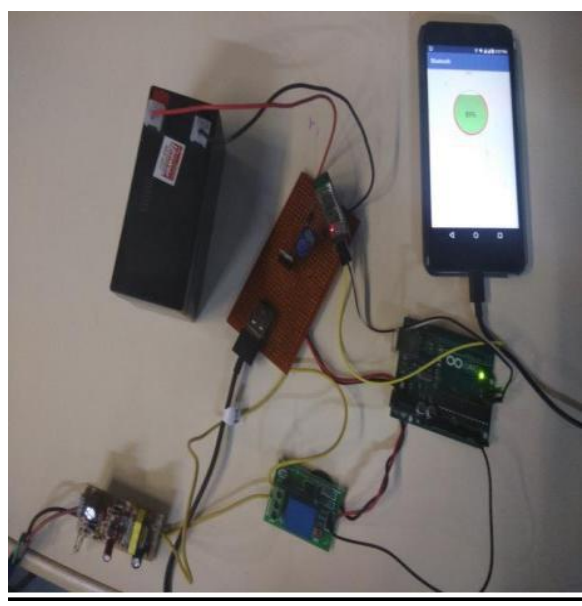

Figure 3.4: Smart Charger Connection

\section{CONCLUSION}

This product is very economical and can be used in any kind of battery charging. As it involves simple components trouble shooting is very easy in case of occurrence of any fault. The product can also be used for various electronic gadgets such as laptops charger and other battery charging technique. Future work will exist with the mantle of this whole electronic circuit parts into a single chip as it will be enclosed within a normal mobile charger adaptor. Hence the charger circuit can wholly transmitted into a portable normal mobile charger with the advanced qualities as a smart charger.

\section{REFERENCES}

1. B. R. Lin, T. L. Hung, C. H. Huang(2003), "Bi-directional single-phase half-bridge rectifier for power quality compensation", IEE Proceedings of Electrical Power Applications, vol. 150, no. 4, pp. 397-406

2. Tanaka, T. Sekiya, H. Tanaka, M. Okamoto, E. Hiraki, "Smart charger for single-phase three-wire distribution feeder", IEEE Transaction Ind. Applications, vol. 49, no. 6, pp. 2628-2635, 2013

3. Sharma, C. Cañizares, K. Bhattacharya, "Smart charging for distribution systems", IEEE Transactions on Smart Grid, vol. 5, no. 3, pp. 1196-1209, 2014.

4. "Automotive USB Battery Charging Reference Design" http://www.ti.com/tool/PMP8851

5. "Trip Circuit Supervision in Switchgear" (http://www.electricalindia.in/blog/post/id/5460/trip-circuitsupervision-in-switchgear)

6. "Power Consumption of mobile charger"(https://www.bijlibachao.com/applian ces/charging-amobile-phone-how-much-electricity-does-it-consume.html

7. Manoj Kumar and Deepak Lanna (2015) “ Design and development of cost effective automatic cut off PV 8. charge controller with indicator", IOSR-JEEE, VOL10, PP18-

8. https://circuitdigest.com/electronic-circuits/cell-phonecharger-circuit-diagram

9. https://www.electronicshub.org/usb-mobile-charger-circuit/

10. https://electronics.stackexchange.com/questions/207738/smps -mobile-charger-design

11. https://dir.indiamart.com/impcat/mobile-phone chargepco.html
Published By: 